al, 1994) or due to depletion of hepatic glutathione resulting from repeated paracetamol overdoses or malnutrition, as in anorexia nervosa (Vale et al, 1995).

Hospital shop managers will be more used to commercial rather than clinical considerations when selling over the counter medication. Therefore, it is not surprising this study showed the danger of selling medication to hospital inpatients was not always identified and when it was, only one shop had devised what appears to be a robust restrictive sales policy. This suggests, for existing or future medication sales on hospital sites, policy should be made by the local psychiatric directorate and hospital management, not by the retailer.

Psychiatrists may want to check for themselves if the hospital shop is selling medication and if so, whether there are adequate restrictions in place to prevent sales to in-patients. The most reliable policy would be to restrict all sales of medication to staff with identification or, more simply, prohibit medication sales entirely.

\section{References}

CRAMmer, J. L. (1984) The special characteristics of suicide in hospital in-patients. British Journal of Psychiatry. 145. 460-476.

JACOBSON, R., JACKSON, M. \& BERELOWTTZ, M. (1986) Selfincineration; a controlled comparison of in-patient suicide attempts. Clinical features and history of selfharm. Psychological Medicine, 16, 107-116.

MAKIN, A. J., WENDON, J. \& WILLIAMS, R. (1994) Management of severe cases of paracetamol overdosage. Britlsh Journal of Hospital Medicine, 52, 210-213.

MORGAN, H. G. \& PRIEST, P. (1991) Suicide and other unexpected deaths among psychiatric in-patients. The Bristol confidential inquiry. British Journal of Psychiatry, 158, 368-374.

VAle, J. A. \& PROUdFoot, A. T. (1995) Paracetamol (acetaminophen) poisoning. Lancet, 346, 547-552.

David Somerfield, Senior Registrar in Rehabilitation Psychiatry, Assessment and Training, 1 Colston Fort, Montague Place, Kingsdown, Bristol BS6 5UB

\title{
Specialised in-patient psychiatric service for women
}

\author{
Dora Kohen
}

\begin{abstract}
Aims and method To describe one of the first psychiatric services in the inner-city especially designated for female psychiatric patients with severe mental illness.

Results The referral system, the staffing levels and the admission criteria have been established following needs of the patients, especially young women with perinatal problems and women from ethnic minorities. Clinical implications This single gender acute psychiatric ward has received welcome attention from mental health professionals and management at every level, and it is hoped that further discussion will help to clarify future policles and guidelines on all aspects of this venture.
\end{abstract}

In the past decade, with the better understanding of vulnerability of women in mixed gender psychiatric wards, several consumer, women and local mental health groups have initiated a discussion around the possibility of having a single gender in-patient unit for acute psychiatric admissions in City and Hackney. In 1991 the Community Health Council first expressed concern about the lack of privacy and sexual assault occurring in mixed gender psychiatric units locally (Tonks, 1992). The mental health charity MIND drew attention to growing potential for sexual assaults on women in mixed psychiatric wards. This was followed by different surveys showing that both men and women experienced sexual harassment and that the majority of women felt vulnerable in mixed wards during the acute stages of their illness. The issue was followed by discussions about segregation of women in single gender wards versus the possibility of giving the choice and offering safety to women who felt vulnerable and preferred single gender wards. 
In 1995 the new psychiatric wing of the Homerton Hospital was completed. This building was to house all the in-patient wards of the City and Hackney Community Services NHS Trust. Psychiatrists and management agreed to establish a pilot women's only ward to study the feasibility of such an acute ward. The need for a women's only acute psychiatric unit is not as widely accepted and therefore this 12-bedded unit for severely mentally ill women in the Psychiatric Wing of the Homerton Hospital in East London, established two years ago, is rare (Subotsky, 1991; Henderson \& Reveley, 1996).

Hopefully the model described here will serve to widen the discussion on the necessity, understanding and philosophy of these services.

\section{Admission criteria}

The admission criteria have been a major training exercise for all involved. While at first instance referrals ranged from the worried well and drug and alcohol misusers to women with psychological problems in need of respite care, the criteria have now been crystallised and the team rarely receives inappropriate referrals.

Establishment of the policies and dissemination of the guidelines for admission and the referral criteria of this women's unit has been a major task. Every discipline was involved in seminars to colleagues, management, local and London-wide general practitioner (GP) surgeries, obstetrics and gynaecology services, community mental health teams and local voluntary organisations.

At present all admissions are severely mentally ill women who would be vulnerable in a mixed gender psychiatric ward and who would warrant an acute psychiatric admission under any circumstance.

It is clear that all psychiatric patients could be classified as vulnerable but the criterion of vulnerability has been defined as 'vulnerable' in their interaction with men.

Table 1 gives the demographic characteristics of patients admitted to the women's ward in one year $(n=324)$. The age range $(16-62 ;$ mean 29$)$ and length of stay (two days-nine months, an average of seven weeks) show the differing needs of a diverse group. Fifty-eight per cent of women were married or cohabiting while $32 \%$ were single at the time of admission.

The final ICD-10 diagnosis (World Health Organization, 1992) show a very similar pattern to any acute psychiatric ward. Forty-one per cent of patients have schizophrenia or other disorders; $25 \%$ have affective disorders, while there is the usual small rate of admissions for organic disorders (2\%); behaviour disorder due to substance misuse (1\%); neurotic or stress-
Table 1. Demographic variables of in-patients in a psychiatric service for women (admissions between April 1996-April 1997), $n=325$

\begin{tabular}{|c|c|}
\hline & $n(\%)$ \\
\hline \multicolumn{2}{|l|}{ Marital status } \\
\hline Single & $103(32)$ \\
\hline Married & $91(28)$ \\
\hline Cohabiting & $99(30)$ \\
\hline Divorced & $27(9)$ \\
\hline Widowed & $4(1)$ \\
\hline \multicolumn{2}{|l|}{ ICD-10 diagnosis } \\
\hline $\begin{array}{l}\text { Delirium and organic disorders } \\
\text { (FO0-09) }\end{array}$ & $5(2)$ \\
\hline $\begin{array}{l}\text { Behaviour disorder to substance } \\
\text { misuse (F10-19) }\end{array}$ & $4(1)$ \\
\hline \multicolumn{2}{|c|}{$\begin{array}{l}\text { Schizophrenia and other disorders } 132(41) \\
\text { (F20-29) }\end{array}$} \\
\hline Affective disorder (F30-39) & $82(25)$ \\
\hline $\begin{array}{l}\text { Neurotic stress-related disorder } \\
\text { (F40-49) }\end{array}$ & $27(8)$ \\
\hline $\begin{array}{l}\text { Mental disorders associated with } \\
\text { puerperium (F53.1-9) }\end{array}$ & $65(20)$ \\
\hline Personality disorders (F60-69) & $9(3)$ \\
\hline \multicolumn{2}{|l|}{ Admission criteria } \\
\hline Pregnancy & $57(17)$ \\
\hline First-episode schizophrenia & $11(3)$ \\
\hline Ethnic minority & 141 (47) \\
\hline Residual schizophrenia & $47(14)$ \\
\hline History of abuse & $51(16)$ \\
\hline $\begin{array}{l}\text { Extra-contractual referral with } \\
\text { above criteria }\end{array}$ & $48(15)$ \\
\hline
\end{tabular}

related disorders (8\%); and personality disorders (3\%). But it is important to note the high number of patients with mental disorders associated with the puerperium (20\%) who make use of this single gender ward at a most vulnerable period of their lives.

Priority of admission is given to pregnant women with a diagnosis of severe mental illness (17\%). After delivery those women are assessed to move on to the adjacent mother and baby unit if necessary. Women who have delivered in the last one year but whose babies are either fostered, in care or cared for by the father or other member of the family are prioritised as well. Young women under the age of 19 who are going through first-episode schizophrenia (3\%) and women in their late 50 s and early $60 \mathrm{~s}$ who find it difficult to cope with noisy and intrusive mixed gender wards are admitted (14\%).

Women who have been physically assaulted in a relationship or have a history of physical and sexual abuse (16\%), those who belong to different ethnic minorities and religious groups (47\%) and finally any women with severe mental illness who request admission are considered. 
Patients are referred by GPs, consultant psychiatrists, members of the obstetrics and gynaecology team, mixed gender ward team, nurses and junior staff in the emergency clinic and members of the four local community mental health teams. The unit has had a large number of referrals, therefore there is a joint assessment team consisting of a rotating $F$ grade nurse and a junior doctor who assess the patient in the accident and emergency department, or maternity wards, the mixed psychiatric wards or in the community prior to admission. Hospital and accident and emergency assessments are done within hours of referral but community assessments are done only on a set day of the week.

The unit has attracted a fair number of extracontractual referrals (15\%) and at any time 15$20 \%$ of the patients are from neighbouring boroughs using the ward for mainly perinatal psychiatric purposes.

\section{Staff}

The staff consist of men and women keen to work in the women's unit. There is a full-time occupational therapist and part-time psychologist, movement therapist and an art therapist. Voluntary organisations have been eager to be involved and to contribute to the patients in the unit. Local organisations such as the Jewish Orthodox Community, and Turkish, Kurdish. Chinese and Muslim organisations have been fully involved in short-term management, Care Programme Approach (CPA) meetings and community follow-up.

\section{Strengths and weaknesses}

The ward atmosphere is peaceful and reasonably private. As compared to mixed wards, the general impression is that it has a smaller share of violence and definite lack of sexual harassment. Only one-half of the patients are on the sections of the Mental Health Act 1983 and only one-third of the patients need special observation at any one time.

Women express a feeling of being more at ease. There have been requests to be transferred to this unit, although there have also been patients who preferred a mixed gender ward and refused to be transferred claiming the ward was monotonous without men. The discharge procedure has been slower for some patients who preferred the atmosphere in the ward to the responsibilities and sometimes isolation at home. The issue of prolonged hospitalisation and resistance to discharge has been tackled by giving an early discharge date in the initial CPA meeting and collaborating with the community keyworker to keep this data. Out-patient occupational therapy programmes, women's groups and mother and baby groups in the hospital which offer continuity of care and structure to their day have been helpful as well.

\section{Comment}

There has been a major interest from other consultant psychiatrists, health service managers, local and community groups, teaching colleges, psychotherapy training groups, medical, nursing, psychology and social work students to visit the ward, to discuss issues related to merits and problems, to attend the ward rounds, to meet with the ward management, to be involved in research and to generally learn more about the functioning of the ward. This has helped to widen the discussion about the needs for women's units and to propagate the idea in other districts.

Preliminary doubts about the feasibility and function of the women's unit have now disappeared. It is enthusiastically accepted that a women's ward has a place in acute general psychiatry. Nevertheless, all professionals involved are aware that they may be opening the floodgates and increasing the referral rates by several folds. But the regularly updated policies and guidelines, the input from the community services and the joint assessment team should be able to continue to support patients in the community.

In addition to adequate acute in-patient facilities, the aim of the unit is to provide a specialised service more responsive to women's changing needs, a better understanding of community health services and a continuous local community forum.

To date there is lack of research that compares aggression, disturbance, patient satisfaction or length of stay in hospital in mixed wards and a women's unit. In the future even if no major differences were to be reported, the privacy and safety provided by the unit, the enthusiasm of the families, the involvement of the local ethnic minorities and women's groups who wish to reorganise the services to suit their needs all make the case for single gender wards.

\section{References}

Henderson. C. \& Reveley, A. (1996) Is there a case for single sex wards? Psychiatric Bulletin, 20, 513-515.

SUBOTSKY. F. (1991) Issues for women in the development of mental health services. British Journal of Psychiatry. 168. (suppl. 10), 17-21.

TONKS, A. (1992) Women patients vulnerable in mixed psychiatric wards. British Medical Joumal, So4, 1331.

WORID HEALTH ORGanization (1992) The Tenth Revision of the International Classification of Diseases and Related Health Problems (ICD-10). Geneva: WHO.

Dora Kohen, Consultant Psychiatrist, Psychiatric Wing, Homerton Hospital, Homerton Row, London E9 6SR 